CLINICAL STUDY

\title{
IGF-I gene promoter polymorphism is a predictor of survival after myocardial infarction in patients with type 2 diabetes
}

\author{
Mojgan Yazdanpanah ${ }^{1}$, Fakhredin A Sayed-Tabatabaei ${ }^{1}$, Joop A M J L Janssen ${ }^{2}$, Ingrid Rietveld ${ }^{1,2}$, Albert Hofman ${ }^{1}$, \\ Theo Stijnen $^{1}$, Huibert A P Pols ${ }^{1,2}$, Steven W J Lamberts ${ }^{2}$, Jacqueline C M Witteman ${ }^{1}$ and Cornelia M van Duijn ${ }^{1}$ \\ Departments of ${ }^{1}$ Epidemiology and Biostatistics and ${ }^{2}$ Internal Medicine, Erasmus Medical Centre, PO Box 2040, 3000 CA Rotterdam, The Netherlands \\ (Correspondence should be addressed to C M van Duijn; Email: c.vanduijn@erasmusmc.nl)
}

\begin{abstract}
Objective: Previously we observed that non-carriers of the most common alleles of an IGF-I promoter polymorphism have low circulating IGF-I levels and an increased risk of developing myocardial infarction (MI), particularly in patients with type 2 diabetes.

Design: We investigated whether this IGF-I promoter polymorphism is associated with survival of type 2 diabetes in a Caucasian population aged 55 years and older.

Methods: The study was embedded in the Rotterdam Study, a prospective population-based cohort study. At baseline, 668 patients with type 2 diabetes were diagnosed, among which, 55 incident MI were ascertained during follow-up. For the present study, we used two genotype groups: non-variant carriers (homozygous for 192, 194, or 192/194 bp genotypes), and variant carriers.

Results: During a median follow-up of 8.8 years, 396 out of the 668 patients with type 2 diabetes $(59.3 \%)$ died of various causes. The frequency of type 2 diabetes variant carrier and non-variant carriers was 28.7 and $71.3 \%$ respectively. The survival in patients with type 2 diabetes without an MI did not differ between the IGF-I genotype groups (hazard ratio $(\mathrm{HR})=0.8,95 \%$ confidence interval (CI): $0.7-1.1, P=0.1)$. In contrast, in those who developed an MI, variant carriers had a 2.4 times higher risk of mortality than non-variant carriers (95\% CI: $1.2-4.8, P=0.01)$.

Conclusion: Our study suggests that genetically determined low IGF-I activity is an important determinant of survival in patients with type 2 diabetes who developed an MI. The IGF-I promoter polymorphism, therefore, may help to predict the future mortality risk in this group of patients.

European Journal of Endocrinology 155 751-756
\end{abstract}

\section{Introduction}

Insulin-like growth factor-I (IGF-I) is a peptide that has an important role in the promotion and maintenance of insulin secretion and $\beta$-cell mass, and in regulation of myocardial structure (1). It is also an important determinant of glucose homeostasis and may play a role in the regulation of cardiovascular function and cardiac muscle survival (1-5). Low IGF-I levels have been associated with an increased risk of cardiovascular disease (CVD) (6-8). In patients with type 2 diabetes, low serum IGF-I levels are common (9) which may play a role in the development of vascular complications of type 2 diabetes $(10,11)$.

Since circulating IGF-I concentrations do not always directly reflect local production in tissues, identification of genetic polymorphisms could help to characterize long-term local and systemic exposure to IGF-I (8). Twin studies have shown that $40-60 \%$ of the individual variation in IGF-I levels is due to genetic variation (12, 13). We have previously studied a polymorphism in the IGF-I gene promoter region, which is associated with circulating IGF-I levels (14). We observed an increased risk of myocardial infarction (MI) in non-carriers of the most common allele (192 bp) of this IGF-I gene promoter polymorphism, particularly among those with type 2 diabetes (14). In later studies, we found that variant carriers of this IGF-I gene promoter polymorphism had lower circulating IGF-I levels (15) and a higher risk of incident heart failure (16). Although patients with type 2 diabetes with an MI have an increased risk of CVD mortality and total mortality (17), the traditional risk factors, such as obesity, hypertension, and smoking partly explained the excess of mortality $(18,19)$. The previously found association between the IGF-I gene promoter polymorphism and the development of MI in type 2 diabetes suggests that this polymorphism might also modify mortality in patients with type 2 diabetes. The aim of this study was to investigate whether this IGF-I gene promoter polymorphism is indeed associated with survival of patients with type 2 diabetes. We investigated this association in patients with and without MI within the Rotterdam Study. 


\section{Materials and methods}

\section{Study population}

This study was embedded in the Rotterdam Study, a population-based cohort study in which all residents of the Rotterdam suburb Ommoord aged 55 years or older were invited to take part. The Medical Ethics Committee of Erasmus University, Rotterdam approved the study. Written informed consent was obtained from all participants. The design of the study has been described elsewhere (20). The baseline data collection was conducted between March 1990 and July 1993. A total of 7983 subjects participated (response rate $78 \%$ ) in the study. Figure 1 presents a flow chart outlining the participation of the present study population.

Information concerning cardiovascular risk factors was obtained by interview and physical examination at baseline. Anthropometric measurements were obtained at the research center. Body mass index (BMI) was calculated as weight in kilograms divided by height in meters squared $\left(\mathrm{kg} / \mathrm{m}^{2}\right)$. Blood pressure was measured twice on the right arm using a random-zero sphygmomanometer. The average of the two blood pressure values was used in the analyses. Information on smoking habits was obtained during the interview, and participants were categorized into current smokers, never smokers, and former smokers.

Blood sampling and storage have been described previously (20). Serum was separated by centrifugation and quickly frozen in liquid nitrogen. Laboratory measurements were performed on non-fasting blood samples. Total serum cholesterol and high-density lipoprotein (HDL) cholesterol levels were determined using an automated enzymatic procedure (21). A diagnosis of type 2 diabetes was made if subjects were treated for diabetes and/or a random non-fasting glucose level of $11.1 \mathrm{mmol} / \mathrm{l}$ or above (22). We have reported previously that the post-load glucose and insulin levels are similar to the fasting post-load levels (23). Type 2 diabetes was diagnosed in 748 patients at baseline.

\section{Follow-up procedures}

For the diagnosis of an MI, the modular ECG analysis system (MEANS) was used. An MI detected without the evidence of symptoms (silent MI) was verified by an experienced cardiologist (24). Data on the incident MI were verified by the research physicians, who collected information from the patients' medical records. The information also included the copies of discharge letters for hospital admissions. The present analyses on mortality are based on follow-up data collected from baseline (1990-1993) until 1 January 2004. Information on the vital status of the participants was obtained at regular intervals from the municipal population registry. After notification, cause and circumstances of death were established by information from general practitioners (GPs). Letters and, in case of hospitalization, discharge reports from medical specialists were obtained. Subsequently, two research physicians (of whom one was a cardiologist) independently coded all causes of death according to the International Classification of Diseases-10 (25). In case

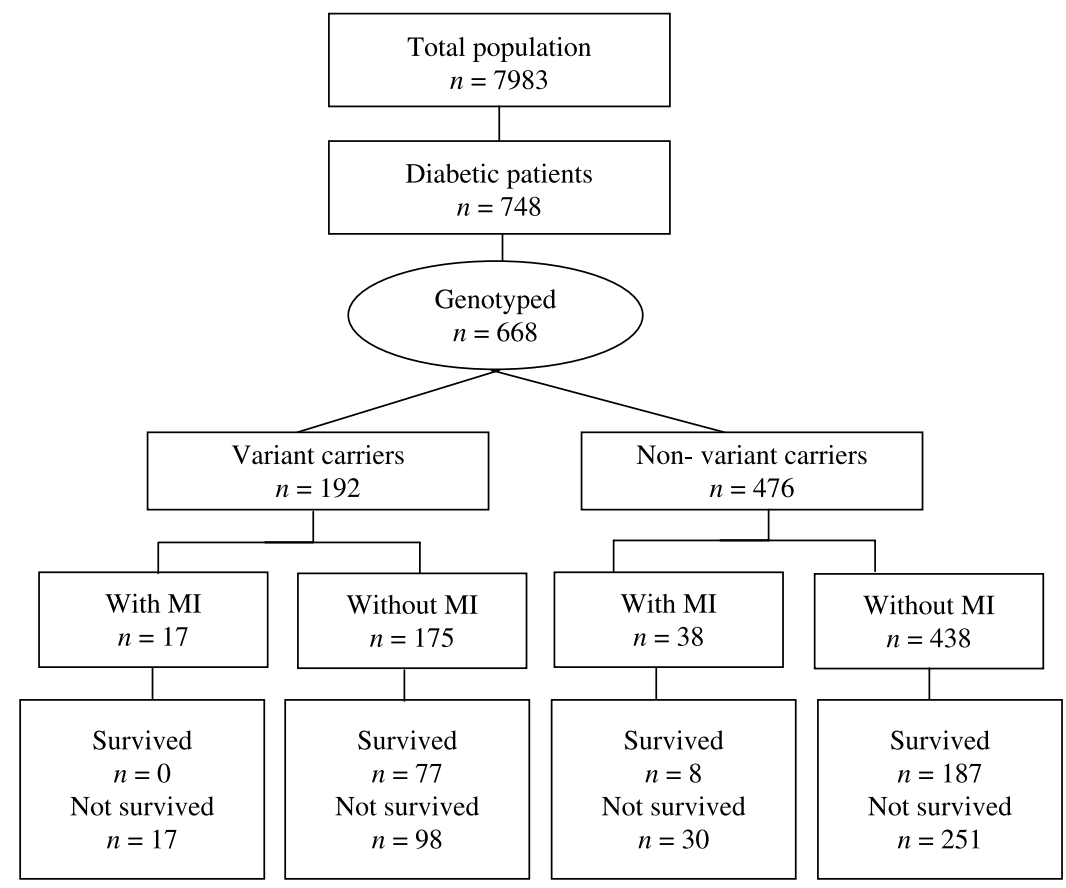

Figure 1 Flow chart outlining the participation of the study population. MI, myocardial infarction. 
Table 1 General characteristics of patients with type 2 diabetes stratified by insulin-like growth factor (IGF)-I genotype. Data are presented as mean \pm S.D.

\begin{tabular}{lccc}
\hline & $\begin{array}{c}\text { Variant } \\
\text { carriers } \\
(n=192)\end{array}$ & $\begin{array}{c}\text { Non-variant } \\
\text { carriers } \\
(n=476)\end{array}$ & $\boldsymbol{P}$ \\
\hline Male gender (\%) & 40.6 & 38.7 & 0.6 \\
Age (years) & $73.7 \pm 9.5$ & $73.4 \pm 8.9$ & 0.7 \\
Body mass index (kg/m $\left.{ }^{2}\right)$ & $26.2 \pm 3.9$ & $27.0 \pm 4.2$ & 0.04 \\
Total cholesterol (mmol/l) & $6.5 \pm 1.3$ & $6.6 \pm 1.3$ & 0.3 \\
HDL cholesterol (mmol/l) & $1.3 \pm 0.4$ & $1.3 \pm 0.4$ & 0.9 \\
Hypertension (\%) & 49.7 & 54.2 & 0.3 \\
Systolic blood pressure (mmHg) & $145.2 \pm 25.0$ & $149.0 \pm 23.4$ & 0.06 \\
Diastolic blood pressure (mmHg) & $72.3 \pm 11.2$ & $73.4 \pm 13.0$ & 0.4 \\
Anti-hypertension medication $(\%)$ & 47.9 & 49.8 & 0.7 \\
Current smoking (\%) & 22.5 & 22.3 & 0.9 \\
\hline
\end{tabular}

HDL, high-density lipoprotein.

of disagreement, consensus was reached. We defined CVD mortality as death from MI or other ischemic heart disease (ICD-10: I20-I25), sudden cardiac death (I46), sudden death undefined (R96), death from ventricular fibrillation or tachycardia (I49), congestive heart failure (I50), or stroke (I60-I64).

\section{Genotyping}

PCR was performed using oligonucleotide primers designed to amplify the polymorphic cytosine-adenosine repeat, $1 \mathrm{~kb}$ upstream of the promoter of the IGF-I gene, as described previously (26). We used a previously described approach, which distinguishes two genotype groups: non-variant carriers and variant carriers (15). As non-variant carriers, we included all subjects homozygous for 192, 194, or having the 192/194 bp genotype (15). As variant carriers, we included subjects heterozygous for 192, $194 \mathrm{bp}$, or non-carriers of these two alleles.

\section{Statistical analysis}

Hardy-Weinberg equilibrium of the IGF-I gene promoter polymorphism genotypes was tested with the $\chi^{2}$ test. We used the $\chi^{2}$ test to compare categorical variables and the two-sample $t$-test to compare continuous variables. Survival curves for the IGF-I gene promoter polymorphisms were estimated by the Kaplan-Meier method and were compared using the two-sample log rank test. Cox's proportional hazards analysis was used to evaluate the contribution of the IGF-I gene promoter polymorphism to all mortality in patients with type 2 diabetes, and subsequently in type 2 diabetes patients with and without an MI. Survival time was calculated as the number of years from entry into the study until the first event or until the end of follow-up. In the subgroup 'without an MI', a subject is censored at the time he/she develops an MI. In patients with type 2 diabetes who developed an MI, survival time after MI was calculated. We examined interaction between IGF-I gene promoter polymorphism and incident MI in predicting survival using Cox's proportional hazards model by including the interaction term in the model. For Cox's proportional hazards analysis, all analyses were adjusted for gender and age, and additionally for known cardiovascular risk factors. Data were analyzed using SPSS for windows version 11.0. All $P$ values were based on two-sided tests and a $P$ value $<0.05$ was considered statistically significant. We applied Bonferroni correction for multiple comparisons and a $P$ value $<0.03$ was considered significant.

\section{Results}

In 668 (89.3\%) patients with type 2 diabetes, the IGF-I gene promoter polymorphism was successfully genotyped. Genotype distributions were in Hardy-Weinberg equilibrium $(P=0.6)$. General characteristics of the study sample stratified by IGF-I genotypes are presented in Table 1. The frequency of this IGF-I gene promoter polymorphism in variant carriers was $28.7 \%$ and in non-variant carriers was $71.3 \%$. No significant difference was observed between the genotype groups for gender, age, cholesterol levels (total and HDL), lipidlowering drugs, hypertension, systolic and diastolic blood pressures, anti-hypertension medication, and smoking. Variant carriers had a significantly lower BMI $(P=0.04)$ and tended to have a lower systolic blood pressure $(P=0.06$; Table 1$)$.

Table 2 Relative risk of mortality in type 2 diabetes stratified by IGF-I genotype and incidence of MI during a mean follow-up of 9.6 years.

\begin{tabular}{|c|c|c|c|c|c|c|c|c|c|}
\hline & \multicolumn{3}{|c|}{ All diabetic patients } & \multicolumn{3}{|c|}{ Diabetic patients without an MI } & \multicolumn{3}{|c|}{ Diabetic patients with an MI } \\
\hline & $\begin{array}{c}\text { Total } \\
\text { subjects }\end{array}$ & Total death & $\mathrm{HR}(95 \% \mathrm{Cl})$ & $\begin{array}{c}\text { Total } \\
\text { subjects }\end{array}$ & Total death & $\mathrm{HR}(95 \% \mathrm{Cl})$ & $\begin{array}{c}\text { Total } \\
\text { subjects }\end{array}$ & Total death & $\mathrm{HR}(95 \% \mathrm{Cl})$ \\
\hline $\begin{array}{l}\text { Variant } \\
\text { carriers }\end{array}$ & 192 & 115 & & 175 & 98 & & 17 & 17 & \\
\hline $\begin{array}{l}\text { Model } 1 \\
\text { Model } 2\end{array}$ & & & $\begin{array}{l}0.9(0.7-1.1) \\
0.8(0.6-1.0)\end{array}$ & & & $\begin{array}{l}0.8(0.7-1.1) \\
0.8(0.6-1.0)\end{array}$ & & & $\begin{array}{l}2.4(1.2-4.8)^{\star} \\
2.7(1.1-6.2)^{*}\end{array}$ \\
\hline
\end{tabular}

$\mathrm{Cl}$, confidence interval; HR, hazard ratio; MI, myocardial infarction; model 1, adjusted for gender and age; model 2, adjusted for gender, age, BMI, serum cholesterol levels (total and HDL), blood pressure (systolic and diastolic), baseline history of cardiovascular disease, and smoking. ${ }^{\star}$ Significant $P$ value $(P<0.03$ after adjusting for multiple comparisons). 


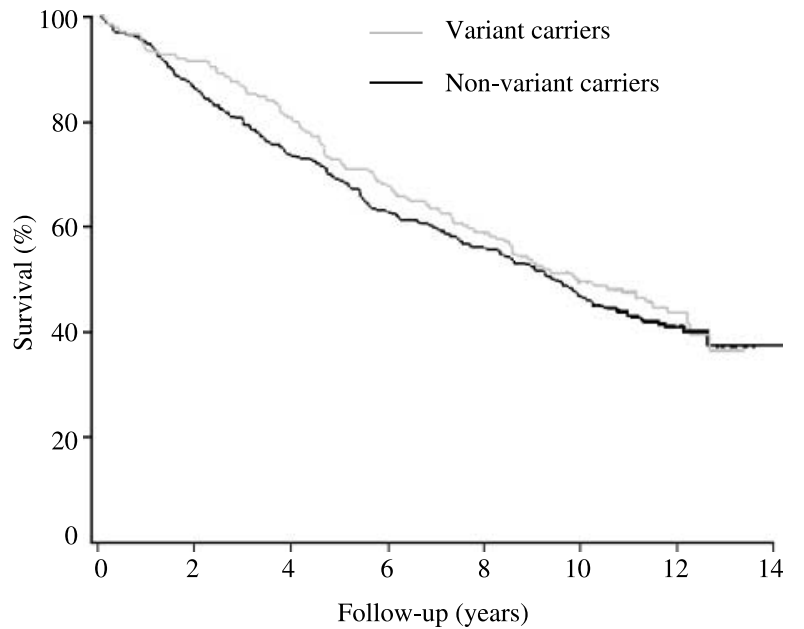

Figure 2 Kaplan-Meier survival curve of all patients with type 2 diabetes stratified by IGF-I genotypes.

The median (s.D.) follow-up time for all patients was 8.8 (4.0) years. During this follow-up, 396 out of the 668 patients with type 2 diabetes $(59.3 \%)$ died of various causes. Mortality due to CVD occurred in $44.5 \%$ of these 396 subjects and was $77.1 \%$ in subjects who developed an MI during follow-up. Table 2 shows the relative risk of mortality in variant carriers and non-variant carriers of this IGF-I gene promoter polymorphism stratified by incident MI. In the whole study sample, the IGF-I gene promoter polymorphism was not significantly associated with risk of mortality (hazard ratio $(\mathrm{HR})=0.9,95 \%$ confidence interval $(\mathrm{CI})$ : $0.7-1.1, P=0.2$, after adjustment for gender and age; Table 2 and Fig. 2).

During the follow-up, 55 patients with type 2 diabetes developed an incident MI, including 18 patients with a history of a prior MI. The median (s.D.) follow-up time after an incident MI was 2.3 (3.5) years. There was no significant interaction between the IGF-I gene promoter polymorphism and incident $\mathrm{MI}$ in predicting survival $(P=0.19)$. No significant association was observed between this IGF-I gene promoter polymorphism and risk of mortality in patients without an $\mathrm{MI}(\mathrm{HR}=0.8$, 95\% CI: 0.7-1.1, $P=0.1$ ) (Table 2 and Fig. 3A). However, variant carriers with diabetes and MI had a
2.4 times higher risk for mortality than non-variant carriers (95\% CI: 1.2-4.8, $P=0.01$; Table 2 and Fig. 3B). This risk increased to 2.7 after further adjustment for cardiovascular risk factors including baseline history of CVD (95\% CI: 1.1-6.2, $P=0.02$; Table 2). These results remained significant after using Bonferroni correction $(P$ value $<0.03)$. When we confined our analysis only to those subjects who died due to CVD, these results did not change $(\mathrm{HR}=2.1,95 \%$ CI: $0.8-5.3, P=0.1$ ). In addition, after excluding patients with a prior MI at baseline, variant carriers with an MI had a 2.3 times higher risk for mortality than non-variant carriers (95\% CI: 1.0-5.7, $P=0.06)$.

\section{Discussion}

In this population-based study, we observed an increased risk of mortality in variant carriers of the IGF-I gene promoter polymorphism among subjects with type 2 diabetes who developed an MI during follow-up. This higher risk of mortality remained significant after further adjustment for clinically relevant cardiovascular risk factors. In patients with type 2 diabetes without an MI, there was no difference in survival between the genotype groups of the IGF-I gene promoter polymorphism.

Our findings suggest that this IGF-I gene polymorphism is particularly important in the survival of patients with type 2 diabetes who have developed an MI. Although we did not measure IGF-I levels in the present study, we previously demonstrated that variant carriers of this IGF-I polymorphism have lower circulating IGF-I levels (15) and a higher risk of incident heart failure (16). In our previous study in non-diabetic subjects (16), we observed that both the short alleles (the two alleles $<192 \mathrm{bp}$ ) and the long alleles (the two alleles $>194 \mathrm{bp}$ ) were associated with significantly lower serum total IGF-I levels (mean (s.E.) $=15.6$ (1.4) nmol/l and $12.0(1.2) \mathrm{nmol} / \mathrm{l})$ when compared with the 192 and the $194 \mathrm{bp}$ alleles. The highest IGF-I levels were observed for homozygous carriers of the $192 \mathrm{bp}$ allele (18.7 (0.6) nmol/l) and homozygous carriers of the $194 \mathrm{bp}$ allele $(17.7(1.4) \mathrm{nmol} / \mathrm{l})$. It has been found that in the early phase of an MI, serum IGF-I levels are often
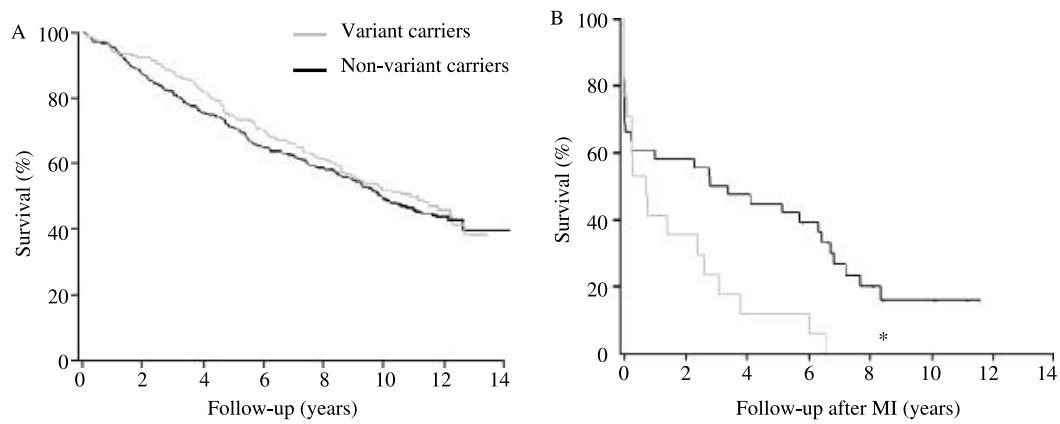

Figure 3 Kaplan-Meier survival curves stratified by IGF-I genotype: in (A) patients with type 2 diabetes without an incident Ml and (B) patients with type 2 diabetes and an incident MI. ${ }^{*} P=0.02$. 
markedly reduced and it has been suggested that this contributes to the adverse outcome $(27,28)$. Another study showed that patients who died after an acute MI during 2 years of follow-up had significantly lowered IGF-I levels at admission compared with survivors (29). Since IGF-I can coordinate a set of actions promoting the survival of myocardial cells (30-32), reduced IGF-I levels may impair the recovery of metabolic cell function after acute MI. Thus, reduced IGF-I may represent a negative prognostic factor, as supported by the study by Friberg et al. (29). Furthermore, it has been reported that low IGF-I levels are related to poor outcome, especially death, in patients with stroke (33). The results of the present study suggest that in patients with type 2 diabetes after an MI, variant carriers of this IGF-I gene promoter polymorphism have a lower survival rate than non-variant carriers. Our results are in accordance with previous studies suggesting that relatively low circulating IGF-I levels are not only associated with an increased risk of developing CVD but also influence survival after an MI $(6,7)$. IGF-I may be a determinant of survival after MI, since it has been demonstrated that it promotes the survival of cardiomyocytes affected by ischemia $(1,27)$. One of the most important actions of IGF-I is an anti-apoptotic effect (30). In various animal models of myocardial ischemia, administration of IGF-I is able to decrease the size of an MI (30). In addition, it has also been suggested that IGF-I reduces angiotensin levels in the heart and interferes with the development of diabetic cardiomyopathy (34). Circulating IGF-I levels may stimulate nitric oxide synthesis and release, and favor glucose metabolism $(35,36)$. Finally, IGF-I may increase cardiac output and myocardial contractility $(27,37)$, and improve the response to ischemia (31, 32). All these IGF-I-mediated effects may influence survival after an MI.

In the present study, since the number of diabetic patients who developed an MI (both in variant carriers and non-variant carriers) was small, the observed increase in the risk of mortality in variant carriers showed a wide confidence interval; and true results may be smaller or larger than the observed results here. We could not find an effect in diabetic patients without an MI; however, we cannot conclude that we would find an effect in a larger population. Because these findings are only observed in subgroups, the results are explorative and need to be confirmed by replication in another population.

In conclusion, our study shows that patients with type 2 diabetes who are variant carriers of an IGF-I gene promoter polymorphism have a lower life expectancy after an MI than non-variant carriers. This IGF-I gene promoter polymorphism, therefore, may help to predict the future mortality risk for patients with type 2 diabetes after an MI. Clinical trials are necessary to investigate how the overall cardiovascular risk in diabetic variant carriers can be improved by IGF-I increasing therapies.

\section{Acknowledgements}

The Rotterdam Study is supported by the Erasmus Medical Center and Erasmus University Rotterdam, the Netherlands Organization for Scientific Research (NWO), the Netherlands Organization for Health Research and Development (ZonMw), the Research Institute for Diseases in the Elderly (RIDE), the Ministry of Education, Culture and Science, the Ministry of Health, Welfare and Sports, the European Commission (DG XII), the Municipality of Rotterdam, and the Centre for Medical Systems Biology (CMSB). The contributions of the general practitioners and pharmacists of the Ommoord district to the Rotterdam Study are gratefully acknowledged.

\section{References}

1 Ren J, Samson WK \& Sowers JR. Insulin-like growth factor I as a cardiac hormone: physiological and pathophysiological implications in heart disease. Journal of Molecular and Cellular Cardiology 199931 2049-2061.

2 Donath MY, Jenni R, Brunner HP, Anrig M, Kohli S, Glatz Y \& Froesch ER. Cardiovascular and metabolic effects of insulin-like growth factor I at rest and during exercise in humans. Journal of Clinical Endocrinology and Metabolism $1996814089-4094$.

3 Donath MY, Sutsch G, Yan XW, Piva B, Brunner HP, Glatz Y, Zapf J, Follath F, Froesch ER \& Kiowski W. Acute cardiovascular effects of insulin-like growth factor I in patients with chronic heart failure. Journal of Clinical Endocrinology and Metabolism $1998 \mathbf{8 3} 3177-3183$.

4 Delafontaine P. Insulin-like growth factor I and its binding proteins in the cardiovascular system. Cardiovascular Research 199530 825-834.

5 Vasan RS, Sullivan LM, D'Agostino RB, Roubenoff R, Harris T, Sawyer DB, Levy D \& Wilson PW. Serum insulin-like growth factor I and risk for heart failure in elderly individuals without a previous myocardial infarction: the Framingham Heart Study. Annals of Internal Medicine $2003139642-648$.

6 Juul A, Scheike T, Davidsen M, Gyllenborg J \& Jorgensen T. Low serum insulin-like growth factor I is associated with increased risk of ischemic heart disease: a population-based case-control study. Circulation 2002106 939-944.

7 Laughlin GA, Barrett-Connor E, Criqui MH \& Kritz-Silverstein D. The prospective association of serum insulin-like growth factor I (IGF-I) and IGF-binding protein-1 levels with all cause and cardiovascular disease mortality in older adults: the Rancho Bernardo Study. Journal of Clinical Endocrinology and Metabolism 200489 114-120.

8 Sandhu MS, Heald AH, Gibson JM, Cruickshank JK, Dunger DB \& Wareham NJ. Circulating concentrations of insulin-like growth factor-I and development of glucose intolerance: a prospective observational study. Lancet 2002359 1740-1745.

9 Tan K \& Baxter RC. Serum insulin-like growth factor I levels in adult diabetic patients: the effect of age. Journal of Clinical Endocrinology and Metabolism $1986 \mathbf{6 3} 651-655$.

10 Goke B \& Fehmann HC. Insulin and insulin-like growth factor-I: their role as risk factors in the development of diabetic cardiovascular disease. Diabetes Research and Clinical Practice 199630 (Suppl) 93-106.

11 Clemmons DR. Role of peptide growth factors in development of macrovascular complications of diabetes. Diabetes Care 199114 153-156.

12 Harrela M, Koistinen H, Kaprio J, Lehtovirta M, Tuomilehto J, Eriksson J, Toivanen L, Koskenvuo M, Leinonen P, Koistinen R \& Seppala M. Genetic and environmental components of interindividual variation in circulating levels of IGF-I, IGF-II, IGFBP-1, and IGFBP-3. Journal of Clinical Investigation 199698 2612-2615. 
13 Li HJ, Ji CY, Wang W \& Hu YH. A twin study for serum leptin, soluble leptin receptor, and free insulin-like growth factor-I in pubertal females. Journal of Clinical Endocrinology and Metabolism 200590 3659-3664.

14 Vaessen N, Heutink P, Janssen JA, Witteman JC, Testers L, Hofman A, Lamberts SW, Oostra BA, Pols HA \& van Duijn CM. A polymorphism in the gene for IGF-I: functional properties and risk for type 2 diabetes and myocardial infarction. Diabetes 2001 50 637-642.

15 Rietveld I, Janssen JA, van Rossum EF, Houwing-Duistermaat JJ, Rivadeneira F, Hofman A, Pols HA, van Duijn CM \& Lamberts SW. A polymorphic CA repeat in the IGF-I gene is associated with gender-specific differences in body height, but has no effect on the secular trend in body height. Clinical Endocrinology 200461 195-203.

16 Bleumink GS, Rietveld I, Janssen JA, van Rossum EF, Deckers JW, Hofman A, Witteman JC, van Duijn CM \& Stricker BH. Insulin-like growth factor-I gene polymorphism and risk of heart failure (the Rotterdam Study). American Journal of Cardiology 200494 384-386.

17 Hu G, Jousilahti P, Qiao Q, Katoh S \& Tuomilehto J. Sex differences in cardiovascular and total mortality among diabetic and nondiabetic individuals with or without history of myocardial infarction. Diabetologia $2005 \mathbf{4 8} 856-861$.

$18 \mathrm{Hu}$ G, Jousilahti P, Barengo NC, Qiao Q, Lakka TA \& Tuomilehto J. Physical activity, cardiovascular risk factors, and mortality among Finnish adults with diabetes. Diabetes Care 200528 799-805.

19 Hernandez C, Francisco G, Chacon P \& Simo R. Lipoprotein(a) as a risk factor for cardiovascular mortality in type 2 diabetic patients: a 10-year follow-up study. Diabetes Care 200528 931-933.

20 Hofman A, Grobbee DE, de Jong PT \& van den Ouweland FA. Determinants of disease and disability in the elderly: the Rotterdam Elderly Study. European Journal of Epidemiology 19917 403-422.

21 van Gent CM, van der Voort HA, de Bruyn AM \& Klein F. Cholesterol determinations. A comparative study of methods with special reference to enzymatic procedures. Clinica Chimica Acta $197775243-251$.

22 Alberti KG \& Zimmet PZ. Definition, diagnosis and classification of diabetes mellitus and its complications, Part 1: diagnosis and classification of diabetes mellitus provisional report of a WHO consultation. Diabetic Medicine 199815 539-553.

23 Stolk RP, Orchard TJ \& Grobbee DE. Why use the oral glucose tolerance test? Diabetes Care 199518 1045-1049.

24 de Bruyne MC, Kors JA, Hoes AW, Kruijssen DA, Deckers JW, Grosfeld M, van Herpen G, Grobbee DE \& van Bemmel JH. Diagnostic interpretation of electrocardiograms in populationbased research: computer program research physicians, or cardiologists? Journal of Clinical Epidemiology $1997 \mathbf{5 0} 947-952$.

25 World Health Organisation. International statistical classification of diseases and related health problems, 10th revision. Geneva. WHO, 1992.

26 Weber JL \& May PE. Abundant class of human DNA polymorphisms which can be typed using the polymerase chain reaction. American Journal of Human Genetics $1989 \mathbf{4 4} 388-396$.
27 Conti E, Andreotti F, Sciahbasi A, Riccardi P, Marra G, Menini E, Ghirlanda G \& Maseri A. Markedly reduced insulin-like growth factor-1 in the acute phase of myocardial infarction. Journal of the American College of Cardiology 200138 26-32.

28 Lee WL, Chen JW, Ting CT, Lin SJ \& Wang PH. Changes of the insulin-like growth factor I system during acute myocardial infarction: implications on left ventricular remodeling. Journal of Clinical Endocrinology and Metabolism 199984 1575-1581.

29 Friberg L, Werner S, Eggertsen G \& Ahnve S. Growth hormone and insulin-like growth factor-1 in acute myocardial infarction. European Heart Journal 200021 1547-1554.

30 Li B, Setoguchi M, Wang X, Andreoli AM, Leri A, Malhotra A, Kajstura J \& Anversa P. Insulin-like growth factor-1 attenuates the detrimental impact of nonocclusive coronary artery constriction on the heart. Circulation Research 199984 1007-1019.

31 Li Q, Li B, Wang X, Leri A, Jana KP, Liu Y, Kajstura J, Baserga R \& Anversa P. Overexpression of insulin-like growth factor-1 in mice protects from myocyte death after infarction, attenuating ventricular dilation, wall stress, and cardiac hypertrophy. Journal of Clinical Investigation $1997 \mathbf{1 0 0} 1991-1999$.

32 Kluge A, Zimmermann R, Weihrauch D, Mohri M, Sack S, Schaper J \& Schaper W. Coordinate expression of the insulin-like growth factor system after microembolisation in porcine heart. Cardiovascular Research 199733 324-331.

33 Denti L, Annoni V, Cattadori E, Salvagnini MA, Visioli S, Merli MF, Corradi F, Ceresini G, Valenti G, Hoffman AR \& Ceda GP. Insulinlike growth factor 1 as a predictor of ischemic stroke outcome in the elderly. American Journal of Medicine $2004117312-317$.

34 Kajstura J, Fiordaliso F, Andreoli AM, Li B, Chimenti S, Medow MS, Limana F, Nadal-Ginard B, Leri A \& Anversa P. IGF-1 overexpression inhibits the development of diabetic cardiomyopathy and angiotensin II-mediated oxidative stress. Diabetes 200150 1414-1424.

35 Walsh MF, Barazi M, Pete G, Muniyappa R, Dunbar JC \& Sowers JR. Insulin-like growth factor I diminishes in vivo and in vitro vascular contractility: role of vascular nitric oxide. Endocrinology 1996137 1798-1803.

36 Russell-Jones DL, Bates AT, Umpleby AM, Hennessy TR, Bowes SB, Hopkins KD, Jackson N, Kelly J, Shojaee-Moradie F \& Jones RH. A comparison of the effects of IGF-I and insulin on glucose metabolism, fat metabolism and the cardiovascular system in normal human volunteers. European Journal of Clinical Investigation 199525 403-411.

37 Cittadini A, Ishiguro Y, Stromer H, Spindler M, Moses AC, Clark R, Douglas PS, Ingwall JS \& Morgan JP. Insulin-like growth factor-1 but not growth hormone augments mammalian myocardial contractility by sensitizing the myofilament to $\mathrm{Ca}^{2+}$ through a wortmannin-sensitive pathway: studies in rat and ferret isolated muscles. Circulation Research 199883 50-59.

Received 10 May 2006

Accepted 29 August 2006 